\title{
The Role of School Leadership in a Large-Scale Student Laptop Implementation
}

\author{
Lee E. Allen, Louis Franceschini, and Deborah Lowther \\ University of Memphis, Memphis, TN, USA
}

\author{
allenlee@memphis.edu; Ifrncsch@memphis.edu \\ dlowther@memphis.edu
}

\begin{abstract}
Researchers have frequently found that leadership plays a key role in the successful and effective implementation of technology in K-12 school districts. A key component of the Michigan Freedom To Learn (FTL): One-to-One Learning initiative evaluation was to obtain valid data from a rigorous and comprehensive research study to gauge the impacts of the program relative to its primary goals. An evaluative research component examining the effectiveness of leadership in FTL initiative as perceived by FTL teachers and lead teachers was added as an extension to the initial multi-year evaluation plan to examine the roles of school leadership (principals, assistant principals, or others) in relationship to the effective implementation of the FTL laptop program.

This paper summarizes the 2007-2008 evaluation results of the leadership survey distributed the to Michigan Freedom to Learn (FTL) program teachers, in their effort to improve student learning and achievement in Michigan schools through the integration of laptop computers with teaching and learning in K-12 classrooms. The results obtained from the survey provided insight into the relationships between the identified leadership attributes and successful program implementation.
\end{abstract}

Keywords: K-12 instructional technology implementation, student laptops, school leadership, administrative roles, levels of support.

\section{Introduction}

The research study presented in this paper summarizes the 2007-2008 evaluation results of a leadership survey distributed to teachers participating in the Michigan Freedom to Learn (FTL) program. The major goal of the FTL program was to improve student learning and achievement in Michigan schools through the integration of $21^{\text {st }}$ Century technology tools with teaching and learning in K-12 classrooms. A key component of the FTL program was a consistent, rigorous, and comprehensive evaluation study designed to gauge the impacts of

Material published as part of this publication, either on-line or in print, is copyrighted by the Informing Science Institute. Permission to make digital or paper copy of part or all of these works for personal or classroom use is granted without fee provided that the copies are not made or distributed for profit or commercial advantage AND that copies 1) bear this notice in full and 2) give the full citation on the first page. It is permissible to abstract these works so long as credit is given. To copy in all other cases or to republish or to post on a server or to redistribute to lists requires specific permission and payment of a fee. Contact 0HPublisher@InformingScience.org to request redistribution permission. the program relative to its primary goals. By providing annual formative evaluations of the program, progress towards the achievement of the program goals could be monitored and interventions could be implemented so as to adjust the program accordingly.

The final evaluative component, the Leadership survey, was not used 
until the end of the five-year annual evaluation period, and thus provides a summative evaluation of the role of leadership in the implementation of the FTL program.

\section{Background}

The primary goal of the Freedom to Learn (FTL) Program as implemented from 2004-2008 was to improve student learning and achievement in Michigan schools through the integration of 21 st Century technology tools - consisting of laptop computers and software - with teaching and learning in K-12 classrooms. The program was developed with the intention of building outward from a 2002-03 pilot program involving fifteen middle schools, "Learning Without Limits". The primary mission of the FTL program was to provide to teachers, administrators, and program professionals with the appropriate professional development. Developing innovative instructional support tools and facilitating access to high quality digital resources were also key targeted goals of the program.

A central component of the FTL initiative was to continuously obtain valid data from a rigorous and comprehensive evaluation study to gauge the impacts of the program relative to its primary goals. The Center for Research in Educational Policy (CREP) at The University of Memphis proposed an evaluative research component as an extension to the multi-year comprehensive evaluation plan. Specifically, the extended evaluation examined the effectiveness of leadership in Michigan's Freedom to Learn (FTL): One-to-One Teaching and Learning Initiative as perceived by FTL teachers and those identified as Lead Teachers.

\section{Purpose of the Study}

Researchers have frequently found that leadership plays a key role in the successful and effective implementation of technology in K-12 school districts (Anderson \& Dexter, 2005; Bliss \& Bliss, 2003; Meltzer \& Sherman, 1997; Schiller, 2002). A key component of the Michigan Freedom To Learn (FTL): One-to-One Learning initiative evaluation was to obtain valid data from a rigorous and comprehensive research study to gauge the impacts of the program relative to its primary goals. An evaluative research component examining the effectiveness of leadership in FTL initiative as perceived by FTL teachers and lead teachers was added as an extension to the initial multi-year evaluation plan to examine the roles of school leadership (principals, assistant principals, or others) in relationship to the effective implementation of the FTL laptop program.

The overall purpose of the summative evaluation was thus to examine the roles of school leadership (principals, assistant principals, or others) in relationship to effective implementation of the FTL laptop program. Evidence of these roles was determined by surveying FTL classroom teachers and Lead Teachers and comparing the results by level of FTL implementation at each school as measured by classroom observation data obtained previously during the initial formative evaluations.

The evaluation had three main goals: (a) to determine which school administrators (principals, assistant principals, or others) were perceived to have fulfilled the primary leadership role effecting implementation of the FTL program; (b) to identify specific roles of school administrators and to what degree that FTL Classroom Teachers and Lead Teachers perceived how the roles affected the FTL program implementation; and (c) to determine if implementation level varied on the basis of leadership roles. Therefore, the research question encompassing the above was:

What is the relationship between the successful implementation of the FTL program and the perception of the teacher participants towards school leaders; and what are the leadership 
traits identified as the most conducive to the successful implementation of the FTL program, as perceived by the teacher participants?

\section{Methodology}

A global descriptive design was used for the evaluation. This design employed a mixedmethods approach (Johnson \& Onwuegbuzie, 2004) utilizing validated data collection instruments. Validated survey and observation instruments, and student performance-based assessments served as the critical data sources in the comprehensive evaluation model. Data collection procedures for the two primary data sources used for this study were the Leadership Effectiveness Assessment Device (LEAD ${ }^{\mathfrak{Q}}$ ) survey plus FTL School Observation Measure $\left(\mathrm{SOM}^{\mathbb{}}\right)$ and the Survey of Computer Use $\left(\mathrm{SCU}^{\mathbb{}}\right)$ data previously collected during multiclass observations.

\section{Instrumentation and Procedures}

Two primary data sources were used for this study: 1) FTL teacher and Lead Teacher responses to the Leadership Effectiveness Assessment Device (LEAD) survey (Appendix) and 2) extant observation data from the School Observation Measure (SOM) and the Survey of Computer Use (SCU) to determine level of FTL implementation at each school. A description of the instruments and data collection procedures follows.

\section{Leadership Effectiveness Assessment Device (LEAD) Survey}

High levels of interest in the impact of principals on school performance have resulted in several national and regionally-based statements of professional standards and issued in a growing number of reviews of the empirical literature. Taking both sorts of documents into account, the Leadership Effectiveness Assessment Device (LEAD) expresses their contents as observable behaviors and maps such behaviors onto a comprehensive model of organizational and leadership effectiveness called the Competing Values Framework (CVF). Within the $L E A D$, the CVF is evoked as an "organizing mechanism, a sense-making device, a source of new ideas, and a learning system" (Cameron, Quinn, DeGraff, \& Thakor, 2006, p. 6) to help articulate "best practices" in educational leadership in way that is more cognitively tractable and growth-enabling.

\section{Development of the competing values framework as a map of effectiveness}

Subjecting a list of effectiveness criteria to the judgments of a panel of organizational theorists, researchers Robert Quinn and John Rohrbaugh (1983) found that most of the similarities and dissimilarities among these judgments could be explained in terms of a perceptual map defined by two major dimensions - specifically, internal versus external focus and centralized control versus decentralized flexibility — and forming four "quadrants." As shown in Figure 1, these four effectiveness quadrants include the following:

(1) the rational goal model, the emphasis of which is on attending to the "bottom line" and articulating a clear course of action to achieve it;

(2) the internal process model, wherein the emphasis is on maintaining a smoothrunning, efficient organization that persists over the long-term;

(3) the human relations model, the emphasis of which is on building teamwork and cultivating employees' skills and competencies; and 
(4) the open systems model wherein the emphasis is on innovation and the acquisition of "slack" resources to support the organization's growth.

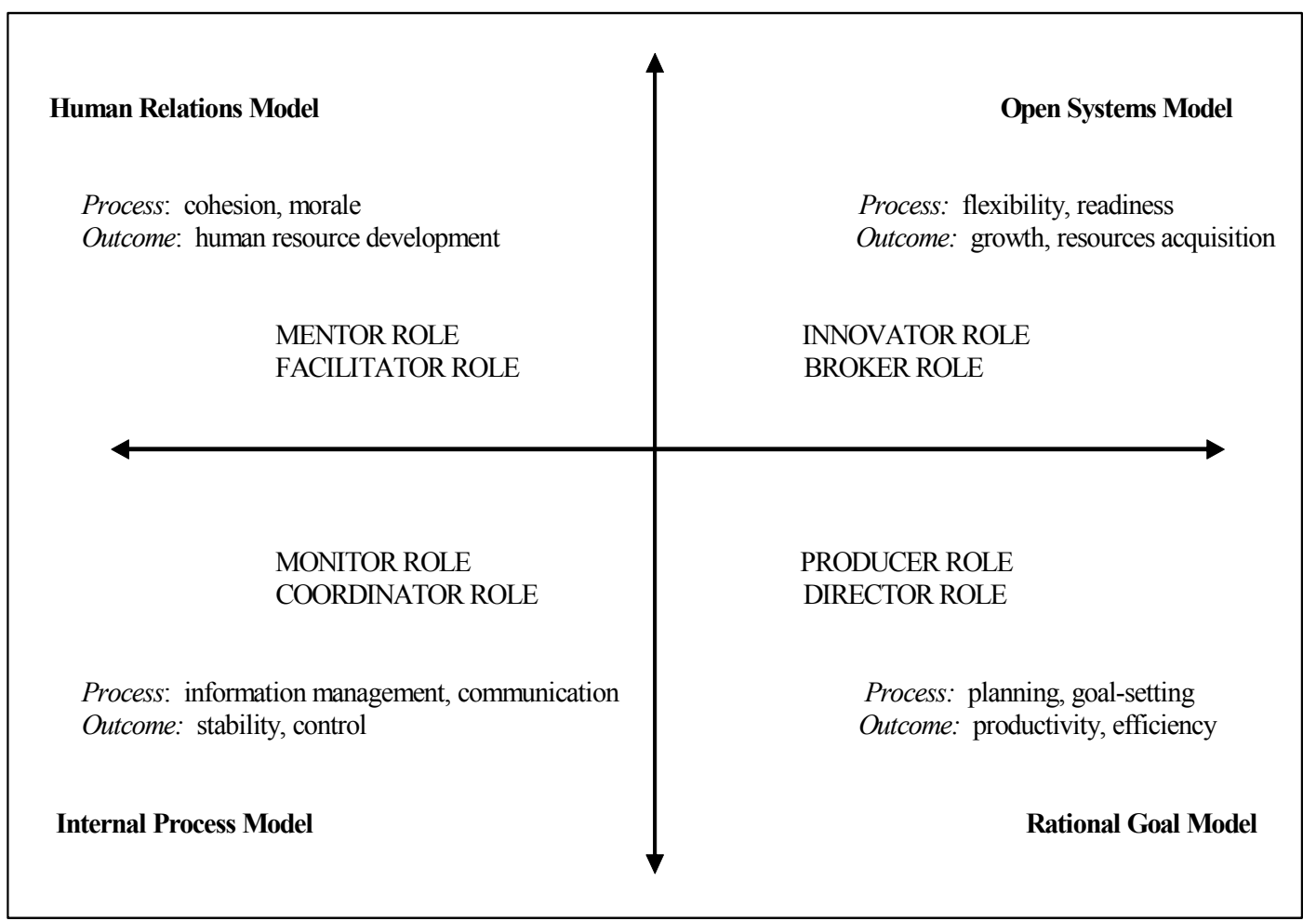

\section{Figure 1. Competing Values Framework: \\ Organizational effectiveness and leadership roles}

Because even- and odd-numbered quadrants were observed to highlight conflicting but critical organizational concerns, the map as a whole was named the Competing Values Framework.

\section{Application of the competing values framework to leadership effectiveness}

Later refinement and application of the CVF to the phenomenon of leadership (see, for example, Cameron, Quinn, DeGraff, \& Thakor, 2006; Quinn, 1984; Quinn 1988; Quinn, Faerman, Thompson, McGrath, \& St. Clair, 2007) suggested the presence of two distinct clusters of activities or "roles" within each of the four effectiveness quadrants: one "role" speaking directly to a particular model's desired outcomes, the other "role" addressing prerequisite processes aimed at those outcomes. Signature activities linked to each of these eight CVF "roles" are as follows:

(1) The innovator role: concerns searching for innovation and improvements, solving problems in creative ways, and envisioning needed changes.

(2) The broker role: concerns exerting upward influence, acquiring needed resources, and spanning boundaries between the organization and its environment.

(3) The producer role: concerns getting the work done, focusing on customer needs, and sustaining an achievement orientation.

(4) The director role: concerns designing a course of action, clarifying priorities; and communicating the organizations goals. 
(5) The coordinator role: involves bringing a sense of order into the workplace and ensuring that organizational processes run smoothly and efficiently.

(6) The monitor role: involves collect information, ascertaining progress, and holding regular reviews of various kinds.

(7) The facilitator role: involves teambuilding engendering cohesion and consensus, and managing interpersonal conflicts.

(8) The mentor role: involves individual capacity building, listening empathically to others' concerns, and treating each staff member in a caring way.

In the vernacular of the Competing Values Framework, the multi-step process that Quinn and his associates (2007) label "becoming a master manager" entails 1) recognizing that there are, in fact, multiple roles to be played (referred to as "cognitive complexity"); 2) acquiring the requisite skills associated with the roles (called "behavioral complexity"); and 3) enacting appropriate roles contingent upon the situation (known as "behavioral differentiation") and in a value-maximizing way (alluded to variously as "interpenetration," "synergy," and "everincreasing integrity").

\section{Application of the competing values framework to educational settings}

Largely developed with for-profit organizations in mind, the CVF has been more often and more completely applied in college and university settings. Within K-12 contexts, the framework has recently inspired empirical studies of school effectiveness (Barath, 1999; Griffin, 2003); but, at present, accounts of how the CVF might be applied to the phenomenon of principal effectiveness have been suggestive only (Davies \& Coates, 2005). Perhaps the most pertinent example concerns a nationwide study conducted in the United Kingdom and entitled Leading Schools in Times of Change (Day, Harris, \& Hadfield, 1999; Day, Harris, Hadfield, Tolley, Beresford, 2000). Therein, researchers associated with the National College of School Leadership (NCSL) explicitly noted how their findings concerning highly effective school "headship" seemed to mirror the structure and dynamics of the Competing Values Framework, which fact prompted them to offer that "it is worth examining further the 'competing values theoretical framework' . . for much may be applied to current and future educational contexts" (p. 168). However, in these same researchers' more recent review of the literature on Successful School Leadership: What It Is and How It Influences Pupil Learning (Leithwood, Day, Sammons, Harris, \& Hopkins, 2006), the CVF is at best employed as an organizing device, albeit with different labels applied to its four quadrants: namely, "building vision and setting directions" substituted for the CVF's rational goal model; "understanding and developing people" replacing the CVF's human relations model; "redesigning the organization" taking the place of the CVF's open systems model; and "managing the teaching and learning program" serving as the proxy for the CVF's internal process model. Table 1 provides the parallels between the 2006 and 2000 NCSL statements. 
Table 1. Structural and thematic parallels between

Leithwood et al. (2006) and Day et al. (2000)

\begin{tabular}{|c|c|}
\hline Leithwood et al., 2006 & Day et al., 2000 \\
\hline $\begin{array}{l}\text { Building vision and setting directions. This category of prac- } \\
\text { tices carries the bulk of the effort to motivate leaders' col- } \\
\text { leagues. It is about the establishment of shared purpose as a } \\
\text { basic stimulant for one's work. The more specific practices in } \\
\text { this category are building a shared vision, fostering the accep- } \\
\text { tance of group goals and demonstrating high performance } \\
\text { expectations. }\end{array}$ & $\begin{array}{l}\text { Rational goal model. In this quadrant the primary emphasis is } \\
\text { on the pursuit and attainment of well-defined objectives; Herein, } \\
\text { norms and values are associated with productivity, performance, } \\
\text { goal fulfillment, and achievement. Motivations are competition } \\
\text { and successful achievement of predetermined ends. Cultural } \\
\text { dimensions which reflect this model are: vision - a concern with } \\
\text { clearly defining where the organization is heading; emphasis on } \\
\text { quality: pressure to produce - where employees feel pressured to } \\
\text { meet targets and deadlines; and performance feedback - where } \\
\text { clear feedback is available about job performance. }\end{array}$ \\
\hline $\begin{array}{l}\text { Understanding and developing people. While practices in } \\
\text { this category make a significant contribution to motivation, } \\
\text { their primary aim is building not only the knowledge and skills } \\
\text { that teachers and other staff need in order to accomplish organ- } \\
\text { izational goals but also the dispositions (commitment, capacity } \\
\text { and resilience) to persist in applying the knowledge and skills. } \\
\text { The more specific practices in this category are providing indi- } \\
\text { vidualized support and consideration, fostering intellectual } \\
\text { stimulation, and modeling appropriate values and behaviors }\end{array}$ & $\begin{array}{l}\text { Human relations model. In this CVF quadrant, the primary } \\
\text { emphasis is on norms and values associated primary emphasis is } \\
\text { on norms and values associated factors are attachment, cohesive- } \\
\text { ness and group membership. Cultural dimensions linked to this } \\
\text { are: concern for employee welfare - the extent to which employ- } \\
\text { ees feel valued and trusted; autonomy - designing jobs in ways } \\
\text { which give employees wide scope to enact work; emphasis on } \\
\text { training - a concern with developing employee skills; and super- } \\
\text { visory support. }\end{array}$ \\
\hline $\begin{array}{l}\text { Redesigning the organization. The specific practices included } \\
\text { in this category are concerned with establishing work condi- } \\
\text { tions which, for example, allow teachers to make the most of } \\
\text { their motivations, commitments and capacities. School } \\
\text { leadership practices explain significant variations in teachers' } \\
\text { beliefs about and responses to their working conditions. Spe- } \\
\text { cific practices are building collaborative cultures, restructuring } \\
\text { and re-culturing the organization, building productive } \\
\text { relations with parents and the community, and connecting the } \\
\text { school to its wider environment. }\end{array}$ & $\begin{array}{l}\text { Open systems model. In this CVF quadrant, the primary empha- } \\
\text { sis is on change and innovation. Herein, norms and values are } \\
\text { associated with growth, resource acquisition and adaptation. } \\
\text { Motivational factors are growth, variety, and stimulation. Cul- } \\
\text { tural dimensions which reflect this orientation are: Outward } \\
\text { forms- Where the organization is attuned to the external envi- } \\
\text { ronment; flexibility; innovation and reviewing objectives - a } \\
\text { concern with reviewing and reflecting upon progress in order to } \\
\text { improve. }\end{array}$ \\
\hline $\begin{array}{l}\text { Managing the teaching and learning program. As with } \\
\text { redesigning the organization, the specific practices included in } \\
\text { this category aim to create productive working conditions for } \\
\text { teachers, in this case by fostering organizational stability and } \\
\text { strengthening the school's infrastructure. Specific practices are } \\
\text { staffing the teaching program, providing teaching support, } \\
\text { monitoring school activity and buffering staff against distrac- } \\
\text { tions from their work. }\end{array}$ & $\begin{array}{l}\text { Internal process model. In this CVF quadrant, the emphasis is } \\
\text { on, stability, internal organization and adherence to rules. Herein, } \\
\text { norms and values are associated with efficiency, coordination and } \\
\text { uniformity. Motivating factors are needs for security, order and } \\
\text { rules and regulations. Scales which reflect this model are: formal- } \\
\text { ization - a concern with formal (often written) rules and proce- } \\
\text { dures; efficiency; and tradition - a concern with maintaining } \\
\text { existing policies practices and procedures. }\end{array}$ \\
\hline
\end{tabular}

\section{Item development and content validation of the LEAD instrument}

Given the perceived usefulness of the CVF in studying school leadership but the absence of an appropriate instrument, recent statements of educational leadership standards (Bottoms \& O' Neill, 2001; Council of Chief School Officers, 1996; National Association of Secondary School Principals, 2004) as well as present and past reviews of research (Cotton, 2003, Hallinger \& Heck, 1997; Leithwood, Day, Sammons, Hopkins, \& Harris, 2006; Leithwood, Louis, Anderson, \& Walstrom, 2004; Marzano, Waters, \& McNulty, 2005) were consulted to determine specific behaviors that aligned with the four quadrants of the CVF and the leadership roles within them. From these documents, a pool of items was developed by doctoral students and faculty members within the Department of Instruction and Curriculum Leadership, College of Education, University of Memphis. To secure content validity, these items were subsequently reviewed by a panel of school principals and professors of educational leadership who were familiar not only with the principal effectiveness literature but also with the CVF itself. Subsequent to this content validity assessment, the items were tested for structural validity by placing the individual items on cards, submitting the cards to a panel of teachers, and asking the panel to sort related items into eight stacks of eight cards. Without prior knowledge of either the CVF or its roles, the panel correctly grouped six out of eight 
items per role, for an average "hit" rate of $75 \%$. For the remaining $25 \%$ that were incorrectly grouped, items that were identified with a CVF role within the same quadrant were merely edited for greater clarity. However, more erratically-grouped items were discarded, alternative effectiveness behaviors were identified, and different items were written to these alternatives.

\section{Classroom Observation Measures}

Trained observers conducted classroom visits to collect frequency data regarding observed instructional practices. The visits were targeted or scheduled in advance with teachers randomly selected from those who participated in the program's technology training. Selected teachers were instructed to deliver a lesson that integrates the use of technology. The data collection instruments were the School Observation Measure ${ }^{\odot}$ (SOM) and the Survey of Computer Use ${ }^{\odot}$ (SCU). The SOM was used to collect data regarding overall classroom activities, while the SCU was used to collect data regarding student use of computers. These classroom observation instruments are described below.

\section{Student Observation Measure (SOM)}

The SOM was developed to determine the extent to which different common and alternative teaching practices are used throughout an entire school or during a targeted lesson (Ross, Smith, \& Alberg, 1999). During this evaluation, it was used to record observations of classroom instruction during prearranged one-hour sessions in which randomly selected teachers demonstrated a prepared lesson for which they were asked to use technology. The observers recorded classroom events and activities descriptively, not judgmentally. Notes forms were completed every 15 minutes of the lesson to record the use or non-use of 24 target strategies and the degree to which a high level of academically focused class time and a high level of student attention/interest was observed. At the conclusion of the one-hour lesson, which typically lasted from 45 to 60 minutes, the observer used a SOM Data Summary Form to summarize the frequency with which each of the strategies was observed. The frequency was recorded via a 5-point rubric that ranges from (0) Not Observed to (4) Extensively. In a reliability study (Lewis, Ross, \& Alberg, 1999), pairs of trained observers selected the identical overall response on the five-category rubric on $67 \%$ of the items and were within one category on $95 \%$ of the items. Further results establishing the reliability and validity of the SOM instrument are provided in the Lewis et al. (1999) report.

\section{Survey of Computer Use (SCU)}

A companion instrument to SOM is the Survey of Computer Use (SCU) (Lowther \& Ross, 2001). The SCU was completed as part of the SOM observation sessions during which SCU data were also recorded in 15-minute intervals and then summarized on an overall data form. The SCU was designed to capture exclusively observable student access to, ability with, and use of computers rather than teacher use of technology. Therefore, in its first section, four primary types of data are recorded: (a) computer capacity and currency, (b) configuration, (c) student computer ability and (d) student activities while using computers. Computer capacity and currency is defined as the age and type of computers available for student use and whether or not Internet access is available. Configuration refers to the number of students working at each computer (e.g., alone, in pairs, in small groups). Student computer ability is assessed by recording the number of students who are computer literate (i.e., easily used software features/menus, saved or printed documents) and the number of students who easily use the keyboard to enter text or numerical information. 
The next section of the SCU records the types of student computer activities, and the subject areas of those activities. The computer activities are divided into four groups based on broad categories of software used: production tools, Internet/research tools, educational software, and testing software. Within each category, more specific types of software are identified. In the Production Tools category, the software types include: word processing, databases, spreadsheets, draw/paint/graphics, presentation, authoring, concept mapping, and planning. In the Internet/research tools category, the software include: Internet browser, CD reference materials, and communications (e.g., email, blogs, websites). In the Educational Software category, the software types include: drill/practice/tutorial, problem-solving and process tools. The Testing Software types include individualized/tracked and generic. With this type of recording system, several activities can be noted during the observation of one student working on a computer. The frequency with which the computer activities and software were observed in use was summarized and recorded using a five-point rubric that ranges from (0) Not Observed to (4) Extensively observed. The subject area of each computer activity was categorized as: language arts, mathematics, science, social studies, other, or none.

The final section of the SCU is an "Overall Rubric" designed to assess the degree to which the activity reflects "meaningful use" of computers as a tool to enhance learning. The definition of meaningfulness is derived from the International Society for Technology in Education's National Educational Technology Standards for Students (NETS-S) (ISTE, 2007). The rubric has four levels: 1 - Low-level use of computers, 2 - Somewhat meaningful, 3 - Meaningful, and 4 - Very meaningful. Reliability data for the SCU (Sterbinsky, Ross \& Burke, 2004 ), show that observer ratings were within one category for $97 \%$ of the whole-school observations and for $91 \%$ of the targeted observations.

\section{Data Collection}

The data collection procedures for the two primary data sources used for this study were: 1) Leadership Effectiveness Assessment Device (LEAD) survey and 2) extant SOM and SCU data are described below.

LEAD Survey: Information regarding online completion of the $L E A D$ survey was distributed via email to the FTL Lead Teachers, who then distributed the information to FTL teachers at his or her school. The information included a brief introduction and overview of the $L E A D$ survey, instructions for completing the online survey, the URL for the survey, and the schoolspecific ID and Password needed to access and submit the survey. The Lead Teachers were contacted beginning February 2008.

Extant SOM and SCU Data: Data from SOM and SCU multi-class observations was used to derive implementation levels for each school. The multi-class observations were used to capture routine classroom practices that typically occur on a regular basis in FTL classrooms. Therefore, this type of observation involves an extended timeframe ( 3 hours) in which multiple FTL classrooms in one school were randomly observed. For instance, one multi-class observation consisted of an observer spending 3 hours in an FTL school conducting 15-minute observations in up to 10 randomly selected FTL classrooms. At the conclusion of the 3 hours, the observer records the frequency with which the various instructional practices were observed.

The 2005-2006 FTL evaluation data was used to determine the implementation level for each of the 86 schools for which multi-class observations were conducted. The SOM and SCU data represent classroom practices that were observed in 599 FTL classrooms. The data was extracted from CREP's Enterprise Class Relational Database and transferred to SPSS for data analysis. 


\section{Results Analyses}

The results of the leadership evaluation study are presented in association with each of the FTL program evaluation research questions in the following section.

\section{What was the composition of the responding FTL sample by schools and respondents within schools as Classroom Teachers, Lead Teachers, or "Other"?}

Of the 124 LEAD survey respondents who completed the 64 item survey, 66 of them identified themselves as FTL Classroom Teachers (53.2\%), while the remaining 58 (46.8\%) identified themselves as either FTL Lead Teachers (50) or some Other Respondent (8).

\section{How did the respondents rate the effectiveness of FTL implementation at their schools, both in the aggregate and by the role played by the respondent?}

Of the $124 L E A D$ survey respondents who both responded to the implementation effectiveness item and completed all $64 L E A D$ items, nearly two-thirds (63.7\%) found the program to have been "largely" (40.3\%) to "very" (23.4\%) effectively implemented at their schools. To determine whether Classroom Teachers or Lead Teachers/Others differed in how they rated FTL implementation effectiveness at their schools, an analysis indicated that there was no statistically significant difference observed among the two respondent subgroups.

3. To what extent did the effectiveness ratings of administrators seen as most responsible for leading the FTL implementation-Principal, Assistant Principal, or "Other Administrator"- differ by a) the type of the respondent providing the rating, b) the kind of administrator being rated, and c) combinations of these variables?

In response to the question concerning which administrator was perceived as being the most responsible for leading the FTL implementation at their location, 69 indicated the "Principal" (55.6\%), six (4.8\%) indicated the "Assistant Principal," and 49 (39.5\%) indicated some "Other Administrator." Among Classroom Teachers, there was no significant difference observed in the FTL implementation effectiveness ratings attributed to Principals/Assistant Principals and Other Administrators. Among the 58 Lead Teachers/Others who completed the survey, no significant difference was found by the two types of administrators rated.

When FTL effectiveness ratings were analyzed irrespective of the type of respondent providing the ratings, no significant differences were observed for either the 75 Principals/Assistant Principals or the 49 Other Administrators. When the type of respondent (as Classroom Teacher or Lead Teacher/Others) was crossed with the kind of implementation leader rated (as either Principal/Assistant Principal or Other Administrator), analyses suggested no statistically significant difference either for the subgroups nested within the 124 LEAD survey completers.

4. To what extent did respondent ratings as to the perceived size of the role played by the leader differ a) the type of the respondent providing the rating, b) the kind of administrator being rated, and c) combinations of these variables?

With respect to the size of the role played by the administrator leading the implementation, sixty-five, or $52.4 \%$, of the $L E A D$ survey completers indicated that the role of the administrator leading the implementation had been "large" to "very large". Only 28 of 124 LEAD survey completers $(22.6 \%)$ offered that the leader had played only a "small" role to "almost no role". With respect to the larger group of 160 respondents, the responses of the 66 Classroom Teachers and 58 Lead Teachers/Others in the group of LEAD survey completers were homogeneous with respect to the size of the leader's role. Notably, the perceived size of the role played in the implementation by the type of administrator as either Principal/Assistant Principal or Other Administrator differed markedly, as Other Administrators were perceived to have played a somewhat larger role. 
Among the 124 LEAD survey respondents, 69 indicated the Principal (55.6\%), six (4.8\%) indicated the Assistant Principal, and 49 (39.5\%) indicated that an Other Administrator played the most significant perceived role in the FTL implementation. Of these 49 Other Administrators, approximately $80 \%$ were variously categorized as "technical advisors", "directors", "consultants", "coordinators", "administrators", "curriculum directors", "instructional specialists", "librarians", "media specialists", "superintendents", and "past administrators". The remaining $20 \%$ of the Other Administrators were categorized as Lead Teachers, Classroom Teachers, or either "no administrator" or some administrator whose exact position was not described. Results indicated that Lead Teachers/Others believed Other Administrators to have played a larger role in the FTL implementation than did either the Classroom Teachers with respect to Principals/Assistant Principals; or Lead Teachers/Others in regards to Principals/Assistant Principals. As rated by Lead Teachers/Others, the role size of Principals/Assistant Principals was significantly lower than the administrative role size of Other Administrators.

\section{To what extent were respondent ratings as to the implementation effectiveness of FTL associated with the perceived size of the role played by the leader according to the role of the respondent, type of administrator being rated, and combinations of these vari- ables?}

For the 124 respondents who completed the $L E A D$ survey, all of the observed correlations between perceived implementation effectiveness and the perceived size of leader's role were homogeneous. When examined by the type of rater, the correlations between ratings of FTL implementation effectiveness and the perceived size of the role of the leader were not significantly different from one another when the responses of the 66 Classroom Teachers and those of the 58 Lead Teachers/Others were examined. Similarly, the correlations appeared to be largely homogeneous by the type of administrator rated: for the 75 respondents who rated Principals/Assistant Principals as playing the most significant leadership role in the FTL implementation, and the 49 respondents who rated Other Administrators as more important.

\section{To what extent did respondent ratings on the eight $L E A D$ scales differ across all FTL respondents and FTL respondent subgroups?}

The data analyses for this question revealed statistically significant multivariate differences among the means on the eight $L E A D$ scales across all 124 respondents and in the interaction of the pattern of differences in the eight scale means across the two different types of administrators thought most responsible for leading the FTL implementation. In comparing the scale means across all 124 respondents, the greatest differences systematically involved the Monitor and Mentor roles. Means for these two roles tended to be significantly lower than means observed for the Producer, Coordinator, Facilitator, Innovator, and Broker roles. In comparing the patterns of differences between the two categories of administrators being rated, a series of independent analyses indicated that FTL Principals/Assistant Principals were perceived as having exercised three $L E A D$ roles more than Other Administrators: specifically, the Director role, the Monitor role, and the Broker role.

\section{To what extent do respondent ratings of FTL implementation effectiveness correlate with the eight LEAD scales and the instrument as a whole?}

For all 124 FTL survey completers, scores on the overall LEAD survey were moderately but significantly correlated with implementation effectiveness ratings. Individual $L E A D$ scales were also statistically related to respondents' perceptions of FTL implementation effectiveness, with the strongest association observed between effectiveness ratings and the nondirective, collegial Facilitator role, and the weakest association observed between effectiveness and its near-opposite, the Director role. With respect to the individual items constituting the Facilitator scale, the strongest correlation was seen between implementation effectiveness 
and the item "makes it easy for teachers to collaborate with one another". Contrastingly, with respect to the individual items constituting the Director scale, the weakest correlation was observed between implementation effectiveness and the item "specifies goals and objectives that guide teachers' planning and everyday practices".

With respect to breakouts of the data by type of rater and the type of administrator rated, the highest correlations were observed between FTL implementation effectiveness and the $\mathrm{Fa}$ cilitator role for Classroom Teachers,; the Producer role for Lead Teachers/Others; the Broker role for those identifying Principals/Assistant Principals as playing the most important FTL implementation role; and the Facilitator role for Other Administrators. Conversely, the lowest correlations that consistently observed in responses by all $L E A D$ survey respondents were between FTL implementation effectiveness and the Director role, for both the Principals/Assistant Principals and for Other Administrator FTL implementation leadership roles.

8. What differences exist among FTL subgroups and their scores on the overall LEAD? Analyses of the $L E A D$ survey response data suggested no statistically significant differences by the two groups of raters (Classroom Teachers and Lead Teachers/Others). However, differences did emerge when the identified leadership roles of the raters was introduced as a factor. Therein, a single significant difference was found; specifically between: 40 Classroom Teachers rating Principals/Assistant Principals, 26 Classroom Teachers rating Other Administrators, 35 Lead Teachers/Others rating Principals/Assistant Principals, and 23 Lead Teachers/Others rating Other Administrators. The analyses employed suggested that Classroom Teachers' ratings of the overall leadership of Principals/Assistant Principals were significantly higher than Classroom Teachers' ratings of Other Administrators.

\section{What relationships between existing school-level scores on the Multi-Class SOM and SCU and FTL Respondent ratings of the implementation effectiveness of the initiative, the size of the role played by the leader, and leadership ratings on the LEAD?}

Data previously obtained at 87 FTL schools on the Multi-Class School Observation Measure (SOM) and the Multi-Class Survey of Computer Use (SCU) were merged with data derived from the present study that had been aggregated from the level of the individual FTL respondent. When the different data files were merged, 40 different FTL school matches were found with respect to the Multi-Class SOM and the Multi-Class SCU.

In investigating the matrix of correlations, the SOM item concerning "Computer for instructional delivery" was seen to correlate positively with five of the $L E A D$ roles; most strongly with the Producer, Facilitator, and Innovator roles, as well as with the overall LEAD. Further, three $L E A D$ scales evidenced robust correlations with the SOM item concerning "High level of student attention/interest/ engagement," specifically, the Producer, Monitor, and Innovator roles. Both the Producer and the Innovator role also correlated significantly with the four-item $S O M$ composite.

With respect to the perceived size of the administrator's role, the strongest correlation observed was for the Computer Usage SOM composite. Although FTL implementation effectiveness did not seem to correlate significantly with any of the individual SOM items, significant correlations were observed between it and the Computer Usage SOM Composite, as well as with the Composite of the Four SOM items [which four?].

At the 28 FTL schools for which $S C U$ data were available on students" "basic" computer skills, the respondents' sense of what FTL implementation effectiveness meant correlated both systematically and robustly with students" "computer literacy" and "keyboarding" skills, and the composite (average) of these two items. With respect to the $L E A D$ scales, systematic and robust correlations were observed particularly between the $S C U$ outcomes and the Mentor and Innovator roles. While the Mentor role was only modestly associated with students' 
"computer literacy" skills, it correlated strongly with students' "keyboarding" skills and the composite of the two $S C U$ "computer basics" items. Even more strongly associated with these $S C U$ outcomes was the Innovator role; that role correlating with both $S C U$ items individually as well as with the composite of the two items. The total $L E A D$ score was observed to correlate especially with students' "keyboarding skills" and modestly with the composite of the $S C U$ "basic skills" items.

At the 40 FTL schools with $S C U$ scores on the Production, Internet, Educational Software, and Testing scales, means were computed for each school by averaging the scores obtained across each of the constituent items. Two of the $S C U$ scales appeared to be associated with respondent perceptions of FTL implementation effectiveness: use of the Internet and use of Educational Software. Associated with four of the eight $L E A D$ scales-specifically, the $D i$ rector, the Mentor, the Innovator, and the Broker roles - as well as the overall LEAD score, was the $S C U$ scale concerning the use of Testing software.

\section{Findings}

The responses from the $L E A D$ survey concerning how effectively the Michigan Freedom To Learn program was implemented indicated that nearly two-thirds of the respondents $(63.7 \%)$ found the FTL program to have been "largely" (40.3\%) to "very" (23.4\%) effectively implemented at their schools. In identifying which administrator played a key role in the FTL implementation, over 55\% indicated the school Principal, approximately 5\% indicated the Assistant Principal, and nearly 40\% indicated Other Administrator. For the 124 respondents who completed the $L E A D$ survey, there were consistent correlations between perceived implementation effectiveness, as measured by previously collected SCU and SOM data, and the perceived size of leader's role.

For the entire group of survey completers, scores on the $L E A D$ survey were moderately but significantly correlated with implementation effectiveness ratings and the following implications can be found in the study's results:

- Overall, the FTL implementation was viewed as successful by a majority of responding constituents.

- Slightly more than half of the respondents viewed their principals as playing the key role as leaders in the FTL implementation.

- A significant percentage of the respondents viewed "others" (neither principals nor assistant principals) as playing the key role as leaders in the FTL implementation.

- While FTL implementation effectiveness did not correlate significantly with any of the individual School Observation Measure (SOM) items, as previously measured in the FTL implementation, some significant correlations were observed between the identified $L E A D$ roles and the Computer Usage SOM Composite:

- Positive correlations were found between five of the identified $L E A D$ roles, and were most evident with the Producer, Facilitator, and Innovator roles, respectively.

- The strongest correlation observed was for the Computer Usage SOM composite and the perceived size of the leader's role.

- Also noteworthy was the correlation found between the perceived size of the leader's role and "High levels of student engagement", specifically in the Producer, Monitor, and Innovator roles. 
- No significant relationships were observed between the Director and Coordinator roles with any of the $S O M$ items or item composites.

- Student computer use (SCU) as previously measured in the FTL implementation was positively correlated with the identified leadership roles of Mentor and Innovator. These are leadership roles defined by personal interaction and risk-taking attributes, respectively.

- The strongest associations, as observed in $L E A D$ survey results, were between effectiveness ratings and the non-directive, collegial Facilitator role; the weakest association observed was between implementation effectiveness and the Facilitator role's nearopposite, the Director role. The Director role is characterized mostly by emphasizing productivity and efficiency goals, and not creative solution-seeking.

\section{Conclusions}

Overall, the Michigan Freedom To Learn implementation was viewed as successful by a majority of responding constituents. Slightly more than half of the respondents viewed their principals as playing the key role as leaders in the FTL implementation, while a significant percentage of the respondents viewed "others" (neither principals nor assistant principals) as playing the key role as leaders in the FTL implementation.

While FTL implementation effectiveness did not correlate significantly with any of the individual School Observation Measure (SOM) items, as previously measured in the FTL implementation, some significant correlations were observed between the identified $L E A D$ roles and the Computer Usage SOM Composite, including positive correlations between five of the identified LEAD roles, with the Producer, Facilitator, and Innovator roles most evident, respectively. The strongest correlation observed was for the Computer Usage SOM composite and the perceived size of the leader's role, with a noteworthy correlation found between the perceived size of the leader's role and "High levels of student engagement" in the Producer, Monitor, and Innovator roles. Interestingly, no significant relationships were observed between the Director and Coordinator roles with any of the SOM items or item composites.

Student computer use (SCU) as previously measured in the FTL implementation was positively correlated with the identified leadership roles of Mentor and Innovator. These are leadership roles defined by personal interaction and risk-taking attributes, respectively.

The strongest associations, as observed in $L E A D$ survey results, were between effectiveness ratings and the non-directive, collegial Facilitator role; the weakest association observed was between implementation effectiveness and the Facilitator role's near-opposite, the Director

role. The Director role is characterized mostly by stressing productivity and efficiency goals, and not creative solution-seeking.

\section{References}

Anderson, R. E., \& Dexter, S. (2005). School technology leadership: An empirical investigation of prevalence and effect. Educational Administration Quarterly, 41(1), 49-82.

Barath, T. (1999). Effectiveness in public education: Models and aspects of leadership. Paper presented at the ENIRDEM Conference, Budapest, Hungary. Retrieved January 2007 from http://www.oki.hu/oldal.php?tipus=cikk\&kod=quality-08-Barath

Bliss, T. J. \& Bliss, L. L. (2003). Attitudinal response to teacher professional development for the effective integration of educational technology. Journal of In-Service Education, 29(1), 81-99.

Bottoms, G., \& O'Neill, K. (2001). Preparing a new breed of school principals: It's time for action. Atlanta, GA: Southern Regional Education Board. 
Cameron, K. S., Quinn, R. E., DeGraff, J., \& Thakor, A. V. (2006). Competing values leadership: Creating value in organizations. Northampton, MA: Edward Elgar.

Cotton, K., (2003). Principals and student achievement: What the research says. Alexandria, VA: Association for Supervision and Curriculum Development.

Council of Chief State School Officers (CCSSO). (1996). Interstate School Leaders Licensure Consortium standards for school leaders. Washington, DC: Author.

Day, C., Harris, A., \& Hadfield, M. (1999, September). Leading schools in times of change. Paper presented at the European Conference on Educational Research, Lahti, Finland. Retrieved December 2007 from http://leeds.ac.uk/educol/ documents/00001242.htm

Day, C., Harris, A., Hadfield, M., Tolley, H., \& Beresford, J. (2000). Leading schools in times of change. Philadelphia, PA: Open University Press.

Davies, P., \& Coates G. (2005). Competing conceptions and values in school strategy: Rational planning and beyond. Educational Management Administration \& Leadership, 33(1) 109-124.

Griffin, J. (2003). Schools as organizational models: Implications for examining school effectiveness. Elementary School Journal, 104(1), 29-47.

Hallinger, P., \& Heck, R.H. (1998). Exploring the principal's contribution to school effectiveness: 1980-1995. School Effectiveness and School Improvement, 9(2), 157-191.

Johnson, R.B., \& Onwuegbuzie, A.J. (2004). Mixed methods research: A research paradigm whose time has come. Educational Researcher, 33(7) 14-26.

Leithwood, K., Louis, K.S., Anderson, S., \& Walhstrom, K. (2004). How leadership influences student learning. New York: The Wallace Foundation. Retrieved June 2005 from http://www.wallacefoundation.org/NR/rdonlyres/E3BCCFA5-A88B-45D3-8E27B973732283C9/0/ReviewofResearchLearningFromLeadership.pdf

Leithwood, K., Day, C., Sammons, P., Harris, A., \& Hopkins, D. (2006). Successful school leadership: What it is and how it influences pupil learning. (Research Report 800). National University of Nottingham. Retrieved June 2007 from http://www.dfes.gov.uk/research/data/uploadfiles/RR800.pdf

Lowther, D. L., \& Ross, S. M. (2001). Survey of Computer Use (SCU). Memphis, TN: Center for Research in Educational Policy, The University of Memphis.

Marzano, R., Waters, T., \& McNulty, B. (2005). School leadership that works: From research to results. Alexandria, VA: Association for Supervision and Curriculum Development.

Meltzer, J. \& Sherman, T.M. (1997). Ten commandments for successful technology implementation and staff development. NASSP Bulletin, 81(585), 23-32

National Association of Secondary School Principals. (2004). Breaking ranks II: Strategies for leading high school reform. Reston, VA: Author.

Quinn, R. E. (1984). Applying the competing values approach to leadership: Toward an integrative framework. In J. G. Hunt, D. M. Hosking, C. A. Schriesheim, \& R. Steward (Eds.), Leaders and managers: International perspectives on managerial behavior and leadership (pp. 10-27). New York: Pergamon.

Quinn, R. E. (1988). Beyond rational management: Mastering the paradoxes and competing demands of high performance. San Francisco: Jossey-Bass.

Quinn, R. E. (2004). Building the bridge as you walk on it: A guide for leading change. San Francisco: Jossey-Bass.

Quinn, R. E., Faerman, S. R., Thompson, M. P., McGrath, M. R., \& St. Clair, L. S. (2007). Becoming $a$ master manager: A competing values approach $\left(4^{\text {th }}\right.$ Ed.). New York: Wiley. 
Quinn, R. E., \& Rohrbaugh, J. (1983). A spatial model of effectiveness criteria: Towards a competing values approach in organizational analysis. Management Science, 29(3), 363-377.

Quinn, R. E., Spreitzer, G. M., \& Hart, S .L. (1992). Integrating the extremes: Crucial skills for managerial effectiveness. In S. Survastra, R. F. Fry, \& Associates. Executive and organizational continuity: Managing the paradoxes of stability and change (pp. 222-253). San Francisco: Jossey-Bass.

Ross, S. M., Smith, L. J., \& Alberg, M. (1999). The School Observation Measure (SOM ${ }^{\odot}$ ). Memphis, TN: Center for Research in Educational Policy, The University of Memphis.

Schiller, J. (2002). Interventions by school leaders in effective implementation of information and communications technology: Perceptions of Australian principals. Journal of Information Technology for Teacher Education, 11(3), 289-301.

Sterbinsky, A., Ross, S. M. \& Burke, D., (2004).Tennessee EdTech Accountability Model (TEAM) Reliability Study. The CNA Corporation, Alexandria, VA.
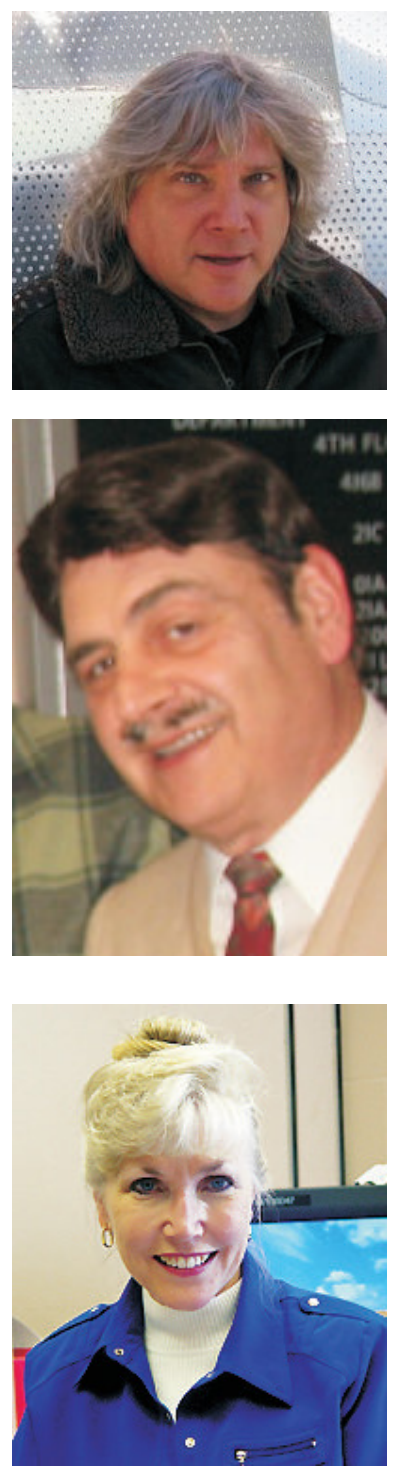

\section{Biographies}

Dr. Lee Allen is an Assistant Professor of Instructional Design and Technology, and has served as the Special Assistant to the Chair of the Instruction and Curriculum Leadership Department for Online Learning and Technology Integration. He has also served as a School District Assistant Superintendent for Technology in Dallas, TX, and as a Technology Administrator in Santa Fe, NM.

Dr. Louis Franceschini is the Senior Research Associate at the Center for Research in Educational Policy (CREP) and adjunct faculty member of the Instruction and Curriculum Leadership Department at the University of Memphis.

Dr. Deborah L. Lowther is a Professor of Instructional Design and Technology and Senior Associate Director for the Center for Research in Educational Policy at the University of Memphis. Her work includes nation-ally recognized research initiatives focused on the impact of technology integration and of school reform in K12 environments. 